\title{
Disseminated Cysticercosis with Asymptomatic Involvement of the Heart
}

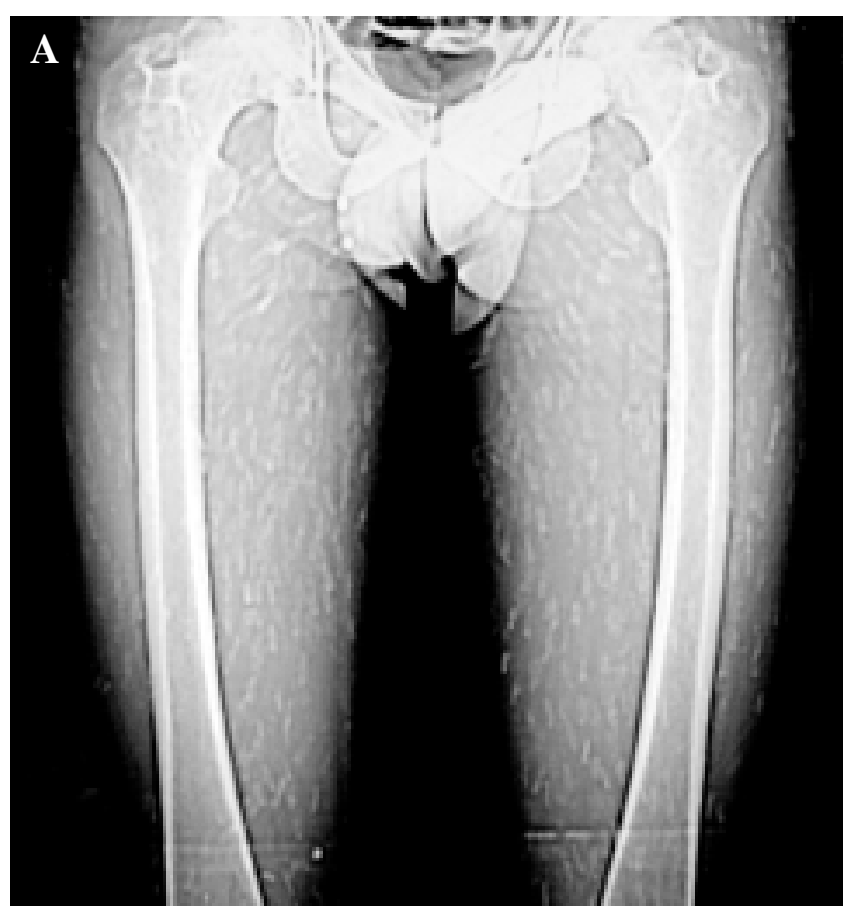

This is a 26-year-old man, admitted to the hospital because of severe headache and generalized seizures of 8 day duration, with an average of 6 to 8 episodes a day. He had a ten-yearhistory of seizures. On physical exam he was oriented, cooperative, with normal vital signs and no neurological abnormality. Multiple small subcutaneous nodules were seen and palpated in several areas of the body, especially on the chest. The remainder of physical examination was normal. A Brain Computed Tomography(CT) showed multiples hypo dense round images in both cerebral hemispheres $(\mathrm{B}$, arrow heads), in some images, hyper dense dots ( $\mathrm{B}$, arrow) were seen in their interior, in others enhancement was present. The radiological picture was consistent with cysticerci in several phases of evolution. X-ray films of soft tissues showed many calcified lesions in muscles of limbs, chest and neck. CT of the thighs showed the same findings (A). Due to the severe involvement of the skeletal muscles an echocardiogram was done and multiple calcified lesions were seen in the heart (C), compatible with cysticerci. A subcutaneous nodule biopsy was diagnosed as Cysticercus cellulosae. Patient was treated with phenytoin, diazepam, dexametasone, ranitidine, thiabendazole and became asymptomatic. Adecision was made not to give specific treatment, based on the number and stages of evolution of lesions. Patient was discharged after one month, taking phenytoin, and prednisone, tapered over several months. One year after discharge patient is doing well taking only phenytoin.
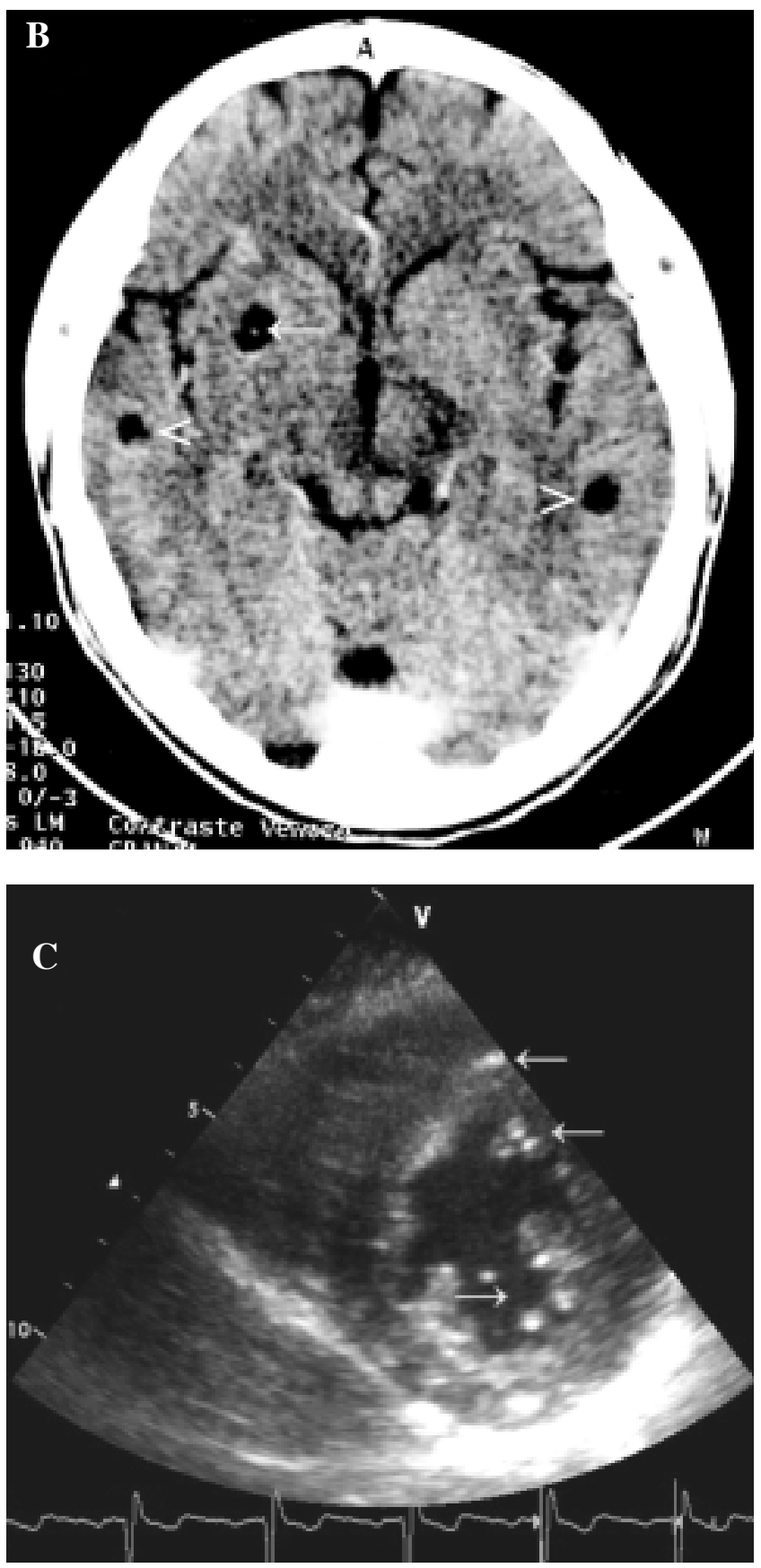

Anastácio de Queiroz Sousa, F. Roberto Neves Solon, J. Eloy da Costa Filho and F. Heli Cavalcante Lima

São José Hospital; Centre of Tropical Medicine of Federal University of Ceará; Fortaleza, CE, Brazil. E-mail:aqsousa@ufc.br 